\title{
Cultura Cultura
}

José Esteves Pereira)

uma leitura atenta

\section{Os códices de Ribeiro dos Santos}

uma leitura atenta

\section{Maria Luísa Cabral}

\section{(2) OpenEdition}

Journals

\section{Edição electrónica}

URL: http://journals.openedition.org/cultura/3673

DOI: $10.4000 /$ cultura.3673

ISSN: 2183-2021

\section{Editora}

Centro de História da Cultura

\section{Edição impressa}

Data de publição: 1 janeiro 2017

Paginação: 81-90

ISSN: 0870-4546

\section{Refêrencia eletrónica}

Maria Luísa Cabral, « Os códices de Ribeiro dos Santos », Cultura [Online], vol. 36 | 2017, posto online no dia 09 setembro 2019, consultado a 06 janeiro 2020. URL : http://journals.openedition.org/cultura/ 3673 ; DOI : 10.4000/cultura.3673

Este documento foi criado de forma automática no dia 6 janeiro 2020.

(c) CHAM - Centro de Humanidades / Centre for the Humanities 


\title{
uma leitura atenta
}

\section{Os códices de Ribeiro dos Santos}

\author{
uma leitura atenta
}

Maria Luísa Cabral

1 São cento e cinquenta os códices que António Ribeiro dos Santos legou à Real Biblioteca Pública da Corte. ${ }^{1} \mathrm{O}$ cuidado posto na sua organização, a exaustividade com que o trabalho foi feito revelam que os códices não serviram apenas para uso próprio de um copiador; não sendo para uso exclusivo, então, a intenção do autor teria de ser outra. Numa prova tipográfica das Memórias para a história da literatura sagrada dos judeus portugueses, Ribeiro dos Santos deixou o seguinte averbamento assinado e rubricado: "Este exemplar impresso [foi] por mim corrigido e acrescentado em algumas coisas por minha própria letra; e por esta razão pertence à classe dos Mss. que devem ir por meu falecimento para a Real Biblioteca da Corte como todos os outros meus" (COD. 4607, 118). Não se consegue perceber pela leitura dos códices se a tarefa ainda começou em Coimbra. Somos inclinados a pensar que talvez não, porque os copistas a que recorreu são pessoal da Real Biblioteca e também porque a continuidade das dimensões físicas dos códices sugere que estes devem ter sido reunidos, cosidos e encapados na mesma oficina (entre cento e cinquenta peças apenas os últimos dezasseis passam a ter um formato maior). Esta não é uma questão central, mas, como apresentação muito sumária do conjunto dos códices, aguça o interesse sobre um manancial informativo que em duzentos anos despertou pouca atenção. Na verdade, entre toda a bibliografia sobre Ribeiro dos Santos, destaca-se o trabalho do Prof. Esteves Pereira (2005); esta constatação deu-nos alguma margem de manobra para procurarmos aprofundar a investigação sobre a obra do bibliotecário. A partir da análise deste estudo, concluímos que importava voltar a reflectir sobre o trabalho de Ribeiro dos Santos como bibliotecário e que também seria interessante escalpelizar o conteúdo e a organização dos códices. É a esta segunda questão que vamos tentar responder.

2 Para compreender o pensamento e acção de Ribeiro dos Santos, não bastará a interpretação dos códices, embora estes constituam uma peça central e incontornável. 
A somar ao elevado número de códices, deparamo-nos com outras dificuldades e linhas de força:

1. A inexistência de índices, sejam temáticos ou onomásticos. Portanto, à medida que se progride na consulta, as dificuldades adensam-se, e se, relativamente às matérias, de uma forma geral o investigador vai registando a novidade do tema ou a sua réplica, o mesmo já não se pode afirmar para o caso de primeiras cópias e cópias posteriores. Existe alguma ordem na forma como os temas se seguem na sequência dos códices. Por exemplo, os primeiros códices são ricos na temática da História; depois há um conjunto sequencial de códices para literatura ou um outro para a história dos judeus portugueses. A própria abordagem sobre as bibliotecas portuguesas não está dispersa. Esta organização muito rudimentar, pouco aperfeiçoada, não deixa de surpreender vinda do homem que tanto dedicou à sistematização dos saberes como instrumento crucial na estruturação da Real Biblioteca.

2. A multiplicação de cópias constitui um enorme obstáculo à consulta dos códices. A cópia de cópia é frequentíssima, e sobre o trabalho do copista ainda há que contar com as alterações e correcções feitas pelo próprio Ribeiro dos Santos, o qual, aliás, não se exime a dar indicações muito concretas: "Vai esse caderno para se copiar que deverá ser o discurso seguido sem os largos que tem" (COD. 4629, 271 v.). Não poucas vezes se encontram averbamentos revelando algum descontentamento com o trabalho do copista. Por exemplo, a determinado passo: "É copiado quase todo dos meus borrões por letra de quem não sabia [refere-se a termos e frases dos clássicos da língua portuguesa] e por isso está aqui com muita imperfeição" (COD. 4648, página título). Há também anotações mais simples, como o caso de um título "Diaconissas" escrito pelo copista e ao lado do qual Ribeiro dos Santos acrescentou "Sobre as". Ou seja, ele não confiava nas cópias, revia e voltava a rever, e por isso se encontram notas como: "É o mesmo que o antecedente", ou "Acabado mas por rever", ou ainda "copiado por Manoel Ayres meu criado sobre os meus primeiros borrões, e já emendado aqui de novo, e copiado em outros cadernos por Bernardino de Sena Branco oficial da Real Biblioteca" (COD. 4596, 231) e "Primeira cópia que se tirou dos meus borrões por Prudencio José Furtado oficial da Biblioteca da Corte. Foi de novo emendada por mim, e já se tirou outra cópia Ribeiro" (COD. 4611, 101 v.). Na prática isto significa que se encontram cópias e várias cópias de cópias, progressivamente mais limpas, até reflectir na íntegra a vontade do autor. Para além de se considerarem os borrões e cópias do mesmo texto com anotações à margem ou em entrelinhas do próprio Ribeiro dos Santos, existem sempre mais versões dispersas por outros códices, também pelo conjunto dos manuscritos avulso, sem mencionar as cópias e os originais existentes noutras bibliotecas, nomeadamente na Biblioteca Pública de Évora.

3. A organização física interna dos códices denota um espírito muito cauteloso, permanentemente a equacionar o eventual reajustamento dos códices. São uma prova deste cuidado as páginas frequentemente deixadas em branco, seja qual for a matéria em que Ribeiro dos Santos esteja a trabalhar, de ordem descritiva e analítica ou de sistematização. Essas páginas com lacunas, intercaladas, estão numeradas, assegurando a ordem dos cadernos. Não se trata de um espaço ao acaso mas deliberado segundo um fio condutor. Um outro pormenor que merece atenção tem a ver com as instruções do próprio Ribeiro dos Santos quanto à encadernação. São muito frequentes notas nesse sentido com, por exemplo, o seguinte teor: "Cozido [sic] com cordéis para acrescentar" (COD. 4671, 97). Portanto, nestas notas, entende-se a encadernação na verdadeira acepção do termo, isto é, formar cadernos.

4. O agrupamento dos conteúdos ajuda a compreender a figura de Ribeiro dos Santos, mas se esta reunião não é perfeita também não se poderá afirmar que é caótica. Devido a essa sequência, por exemplo, os primeiros códices incluem estudos e apontamentos sobre história eclesiástica e sagrada; depois segue-se um grupo de códices sobre o problema do monetário existente na Real Biblioteca, e assim sucessivamente. Organizados pela temática, trabalho do seu punho ou de copistas, os códices contêm textos teóricos ou doutrinários, 
tabelas com propostas de classificação sobre assuntos tão variados como História de Portugal e História Eclesiástica, Doutrina e Disciplina Eclesiásticas, Geografia e Corografia Hispânicas, a Lusitânia Romana, a Hispânia sob o Império Romano, Cartografia, Poesia Portuguesa, Literatura Sagrada dos Judeus Portugueses, Escritores Eclesiásticos, Tipografia em Portugal, Bibliografias, Numismática, Poetas Didácticos, Botânica, Poesia de Elpino Duriense, Legislação Portuguesa, Língua Portuguesa, História da Grécia e Roma, Gramática, Bibliotecas, entre outros, para não referir os manuscritos que foram impressos e de que ele também dá notícia. Ribeiro dos Santos cita autores, transcreve, opina, traduz, concretiza e expõe o seu próprio pensamento. Não será uma compartimentação feita a régua e esquadro; mas existe algum cuidado em incluir, em códices sequenciais, a mesma matéria, e essa é uma das razões para explicar as páginas em branco que vai deixando à medida que o trabalho avança. Pelo sim pelo não, na organização a que se lança dos seus papéis, se aparecer algum documento sobre uma temática previamente tratada, e tendo em conta o cuidado que foi tendo para que os cadernos se possam acrescentar, podem ser adicionadas sempre novas achegas. Esta maneira de trabalhar é particularmente perceptível quando está em causa a organização de bibliografias, as mais das vezes para aquisição. É o caso do Catálogo de Livros escolhidos da História da França (COD. 4622, 46 e seg.) composto de várias entradas que se sucedem - por exemplo, Flandres, Normandia, Bretanha -, mantendo fólios em branco obviamente à espera de serem completados com a bibliografia correspondente. Estes códices assim estruturados são, portanto, documentos de trabalho.

5. A datação dos códices é inexistente, embora no meio desta amálgama exuberante se encontrem documentos preparados ainda em Coimbra ${ }^{2}$ e outros já do período de Lisboa; mas tudo foi organizado e devidamente agrupado por ele próprio em vida, sensibilizado para a necessidade de garantir ordem aos seus papéis, os quais projectava deixar à Real Biblioteca, como veio a acontecer. Os códices per se não estão datados, mas, aqui e acolá, aparecem documentos de Ribeiro dos Santos com data: 1773 data bastante precoce (COD. 4608, 1), 1774 (COD. 4585, 5), 1799 (COD. 4680, 296 v.), 1802 (COD. 4713, 81), 1807 (COD. 4714,148) ou 1817, data muito tardia (COD. 4588, 307 v.). Estas datas deverão ser consideradas meramente indicativas e o seu mais valioso contributo é confirmarem que a organização dos códices é temática, nunca cronológica. Na realidade, a ajuda mais substancial para esta ambição de querer situar no tempo os códices descobre-se nas referências bibliográficas que Ribeiro dos Santos vai citando. Por exemplo, ao acrescentar em nota de rodapé uma obra editada em 1810 , ficamos a saber que aquele códice é posterior e, neste caso, relativamente à vida de Ribeiro dos Santos, até bastante tardio. Há vários casos semelhantes.

6. O conhecimento da bibliografia e das grandes bibliotecas está presente ao longo dos códices. Seja para que matéria for, a preocupação em adquirir bibliografia actualizada é permanente. Não dispomos de informação que esclareça como e quando se processou a organização dos códices, mas sabemos que, no caso da Real Biblioteca, a sua preocupação em adquirir livros para a novíssima biblioteca deve ter começado pelo menos a partir de 4 de Março de 1796, quando Ribeiro dos Santos é nomeado seu Bibliotecário-Mor. Com este pressuposto, podemos datar todas as propostas para aquisição de bibliografia para a Real Biblioteca de 1796 em diante. Ora, destinadas à Real Biblioteca, aparecem muitas referências a obras editadas em datas muito próximas, o que simplesmente significa: que a informação, por via de catálogos ou por correspondência, proveniente dos grandes centros europeus como Paris, Roma ou Londres, circulava muito depressa; que Ribeiro dos Santos tinha acesso a esse circuito; que era um homem informado; que se interessava; que os mercadores livreiros, naturalmente em Lisboa, sabiam bem quem ele era, conheciam os seus interesses e, portanto, não desperdiçavam essa oportunidade de negócio. Ribeiro dos Santos refere amiúde existências noutras bibliotecas, e citamos, a título de exemplo, bibliotecas de Paris, Amesterdão ou Berlim (COD. 4614, 32 e seg.), ou a Bodleiana (COD. 4604, 12 v.). A sublinhar este argumento sobre os conhecimentos bibliográficos actualizados de Ribeiro dos Santos ainda são mais eloquentes as observações que ele anota sobre algumas obras. Entre outros 
casos, vejam-se estas anotações: “Todas as obras editadas em Paris 1698. Há uma edição de Holanda que é mais acrescentada" (COD. 4615, 115) ou ainda "a edição de Paris de 1682 é a melhor" (COD. 4615, 115).

7. A sistematização dos saberes é uma constante, independentemente da temática. Ao folhear os códices, tropeçamos em tabelas muito diversificadas, com maior ou menor profundidade, tabelas a que frequentemente o autor designa de "distribuição metódica". A preocupação com a sistematização fica patente nos vários esquemas que Ribeiro dos Santos vai propondo para arrumação das colecções, recorrendo ao adjectivo "metódico", para que não restem dúvidas, quer quanto às suas preocupações, quer quanto à fundamentação do seu pensamento. Vários exemplos comprovam esta afirmação: "Planos de Distribuição metódica para certas classes de livros pelo $D^{\text {or }}$ António Ribeiro", "Distribuição metódica de um Museu Mineralógico e de seus livros", "Distribuição metódica das matérias de Botânica para servir à classificação dos livros desta faculdade", "Distribuição metódica para se arranjarem os livros e tratados de diversas classes na Real Biblioteca de Lisboa pelo $D^{\text {or }}$ António Ribeiro. Aqui estão somente algumas folhas que se iam tirando a tempo para formarem depois o sistema geral da arrumação" e ainda a "Notícia da Distribuição Metódica de todos os Livros, Mss. e Peças da Real Biblioteca da Corte" (COD. 4683, 168-180). Ribeiro dos Santos preocupava-se em definir o quadro mental e classificativo de cada ramo do saber antes de avançar, fosse para a aquisição de obras, fosse para a organização interna da Real Biblioteca. Esta identificação com os princípios da Enciclopédia sintoniza Ribeiro dos Santos e o seu trabalho com as Luzes, mas não será a única razão que o coloca, e aos trabalhos em que se envolveu, na modernidade. Nos códices tanto encontramos testemunhos da sua sensibilidade e conhecimento daquelas matérias mais expectáveis, como a História, a Igreja, a Filologia, as Ciências Naturais ou a Jurisprudência como nos deparamos com propostas de classificação para as temáticas menos esperadas. É o caso "Das artes Pantomímicas", em que inclui a linguagem para surdos-mudos (COD. 4683, 163). Surpreendente, no mínimo. Muito esclarecedor quanto ao espírito organizador de Ribeiro dos Santos é o “Tratado da imitação das Belas Artes pelo D or. António Ribeiro" (COD. 4667, 35-41), no qual, a determinada altura, se apresentam umas tabelas que enumeram os vários elementos das Belas Artes e esquemas com chavetas na tentativa de explicar e clarificar como se o autor estivesse a arrumar alguma coisa. Com a História das Bibliotecas, o esquema de classificação é particularmente interessante, porque se percebe como Ribeiro dos Santos bem compreendia a necessidade de introduzir uma boa organização nas bibliotecas, como se aí residisse a chave para o conhecimento, como se tudo dependesse do sucesso dessa organização. Assim, dentro da História das Bibliotecas separa a História Geral (onde inclui um título para a Disposição, Arranjamento e Ornamento das Bibliotecas) da História Particular (onde considera os seguintes dez títulos: das Bibliotecas Antigas; das Bibliotecas Modernas; das Bibliotecas de Certas Ciências; das Bibliotecas Nacionais; das Bibliotecas de diversas Corporações; das Bibliotecas Particulares; das Bibliotecas Perdidas; Da Maneira de formar arranjar e distribuir as Bibliotecas; Dos Meios de as enriquecer; Da Maneira de classificar os Autores, e formar os Catálogos) (COD. 4716, 110-110v.). Também aqui está presente a preocupação em sistematizar, persistente e exaustivamente.

A maior parte das vezes, é facilmente perceptível se a tabela metódica se destina à estruturação do pensamento ou se, pelo contrário, se destina a garantir a aquisição de obras; mas em ambas, logo no início do respectivo esquema, lá vem o cuidado com o método merecendo rubrica própria, como acontece na classificação dos livros de História: na primeira rubrica, História Universal, na classe Introdução, Aparatos e Subsídios, o primeiro nível é dedicado a Métodos de escrever, ler e estudar a História (COD. 4583, 38-41). Seja em que circunstâncias for, o que transparece sempre é a preocupação de Ribeiro dos Santos em manter a coerência do esquema, destacar o método, introduzir a sistematização como regra. Como se este esquema fosse uma língua universal que se transforma numa plataforma de entendimento que possa 
constituir "uma via directa de acesso aos outros e ao mundo que garanta um conhecimento adequado e universalmente partilhável" (Pombo 1997, 17).

1. Os códices como um testemunho de vida profissional e, portanto, como arquivo pessoal. Quando se olha para os códices, pode pensar-se que eles foram organizados como copiador onde se encontram cópias e borrões, todos autenticados quer por rubricas de Ribeiro dos Santos, quer pelas próprias emendas e melhoramentos que introduziu. Mas os códices são mais do que isso. Estão ali guardadas as provas da actividade profissional desenvolvida; mais interessante, estes documentos são inúmeras vezes colocados na sua verdadeira dimensão pelas observações que Ribeiro dos Santos regista, assinalando as circunstâncias em que o trabalho foi executado. As mais das vezes, trata-se de trabalhos da sua iniciativa: "Fragmento de uma oração académica que fiz para a abertura de uma cadeira sintética de Direito Romano na Universidade" (COD. 4651, 242), mas também podem corresponder a um favor ou alguma ordem, como é o caso da "Minuta da súplica que se fez para Roma sobre a desmembração do Mosteiro de Belém a qual me foi encarregada por ordem da Secretaria de Estado" (COD. 4651, 248). Desde as intervenções na Universidade de Coimbra como lente até pareceres de carácter jurídico sobre questões de navegação ou do foro eclesiástico, passando pelos planos de estudo para as Escolas Reais de S. Vicente de Fora e a organização da Real Biblioteca, Ribeiro dos Santos foi absolutamente incansável.

2. A atenção dada às bibliotecas portuguesas é uma faceta fundamental na intervenção pública e profissional de António Ribeiro dos Santos, que se preocupa com a situação das bibliotecas portuguesas em geral, e não apenas com a de Coimbra ou a de Lisboa. Os vinte e um códices onde descreve o panorama existente ou adianta propostas são o melhor testemunho do seu profundo envolvimento. Conhece as bibliotecas e as casas nobres ou eclesiásticas onde se albergam, e não se coíbe de discorrer largamente sobre os livros que enriquecem cada uma dessas bibliotecas, bem como os seus proprietários actuais ou anteriores. Dando largas ao seu discurso, acaba por elaborar uma verdadeira história da edição em português com anotações sobre a existência de livros, alguns referenciados por D. Manuel do Cenáculo, Bispo de Beja, a sua localização em diversas bibliotecas, notas sobre a tradução e outras de carácter biobibliográfico. O COD. 4604 testemunha abundantemente o conhecimento e erudição de Ribeiro dos Santos nestas matérias. O autor enumera muitas obras e livrarias particulares de referência, como as bibliotecas do Cardeal Cunha, do Principal Castro da Universidade de Coimbra ou do Convento de Brancanes (Franciscanos) em Setúbal, o que, no seu conjunto, fornece informação útil sobre a circulação de ideias, sobre os livros e seus possuidores. Do ponto de vista organizativo, nos códices encontramos alguns documentos centrais quer para a Biblioteca Joanina, como a Minuta para o Regimento da Livraria da Universidade de Coimbra... (COD. 4676, 189 e seg.), quer para a Real Biblioteca, com o Resumo da Constituição e Estado da Real Biblioteca da Corte [pelo $\mathrm{D}^{\text {or }}$ Antonio Ribeiro Bibliothecario Maior] (COD. 4677, 1 e seg.). Mas são as listas de livros que mais impressionam, como a Lista de alguns livros de que necessita a Bibliotheca de Lisboa (COD. 4631, 131) ou o catálogo de livros Para surtimento da Real Biblioteca de Lisboa pelo $D^{\text {or }}$ António Ribeiro: Encomenda de obras periódicas de França. Encomenda de obras periódicas de Espanha. Encomenda de obras periódicas de Alemanha (COD. 4631, 309 e seg.). São sempre listas massivas de títulos, enriquecidas com observações sobre a edição mais aconselhada, ou porque é a mais recente, ou porque a qualidade do papel é a melhor. Apontamentos ou não, depois de passados a limpo, podem ter constituído encomendas a livreiros. Os assuntos são muito variados: um Catálogo dos Livros de Botânica que há na Real Biblioteca da Corte pelo $\mathrm{D}^{\text {or }}$ António Ribeiro, mas também um Catálogo de Livros escolhidos das artes mecânicas e liberais, incluindo Belas Artes, onde à cabeça vem a Encyclopédie, edição de Paris. Des Arts et Métiers faites ou approvées par Messieurs de l'Académie Royale des Sciences de Paris par J. E. Bertrand a Neuchatel, 1771 (COD. 4626, 95-96) e a Encyclopédie methodique nouvelle edition enrechi de remarques dediée a la Serenissime Republique de Venese. Arts et Metiers Mechaniques, Padua, 1784 (COD. 4626, 96 v.); no mesmo âmbito, surge um Catálogo de nobiliários gerais, uma Lista dos livros de itinerários e viagens que há 
na Real Biblioteca da Corte (COD. 4623, 140, 160) e ainda uma listagem de periódicos da qual destacamos o periódico português Bibliotheca das Sciencias, Porto (COD. 4623, 169), outro periódico português, ainda que tradução, o Jornal Enciclopédico, Lisboa (COD. 4623, 169 v.), ou ainda um periódico alemão editado em Nuremberga (COD. 4623, 171). Os seus apontamentos revelam conhecimentos muito vastos e actualizados (por exemplo, na Botânica ou Física cita autores como Lineu, Buffon ou Pascal) que tenta arduamente organizar de forma a incorporar essa informação na biblioteca. Ribeiro dos Santos pensa nos livros necessários à Real Biblioteca, mas não descura as questões organizativas propriamente ditas. Na secção Tratados sobre os Livros e Bibliothecas (COD. 4630, 126-127v.) cita obras que dão indicações sobre o conteúdo de bibliotecas, mas também sobre como constituí-las. Refere o livro de Naudé (ed. 1627), bem como o de Le Gallois (Traité des plus belles bibliothèques de l'Europe (...), ed. 1680), duas obras de referência para as bibliotecas.

3. A Real Biblioteca ocupa lugar de destaque nos códices e na vida de Ribeiro dos Santos, e as provas são abundantes. Da sua presença nos códices, temos vindo a falar. A partir do momento em que é nomeado para a Mesa Censória (a 3 de Janeiro de 1795), começa um novo período da vida de Ribeiro dos Santos que se prolongará até 1816. Não é um período muito extenso, mas a intensidade com que o vive é indubitável. Centrar-nos-emos na relação estabelecida com D. Rodrigo de Sousa Coutinho, a quem, como Ministro da Fazenda, cabia a tutela da Real Biblioteca no papel de Inspector-Geral. ${ }^{3}$ Para demonstrar essa colaboração, vale a pena referir a aquisição do núcleo bibliográfico Bodoni, muito significativo para a Real Biblioteca (COD. 4631, 318 v.). Outro momento bem esclarecedor deste bom entendimento entre Bibliotecário-Mor e Inspector-Geral da Real Biblioteca é o da criação de uma rede de correspondentes para adquirir obras para a biblioteca (não exploramos este episódio neste artigo apenas porque ele não é objecto de menção nos códices). Há, pois, códices que denunciam com muita clareza a cumplicidade que se estabeleceu entre Ribeiro dos Santos e Sousa Coutinho. Pelo seu percurso de vida, Sousa Coutinho era a pessoa talhada para tutelar a Real Biblioteca, não tendo deixado os seus créditos por mãos alheias. Foi uma tutela curta mas singular e decisiva. A testemunhar esta parceria, por mais de uma vez identificamos nos códices pequenas notas de Ribeiro dos Santos que remetem para Sousa Coutinho, como "Adições que fez o Exmo Snr D. Rodrigo de Sousa Coutinho à encomenda de obras periódicas" (COD. 4615, 140) ou "foi copiada e a cópia ficou na mão de D. Rodrigo" (COD. 4631, 335); há também uma sugestão de D. Rodrigo para a compra de um periódico alemão e a dúvida do Bibliotecário-Mor: "ignoro se continua" (COD. 4631, 312). A própria aquisição do núcleo bibliográfico de Bodoni concretiza-se no tempo de Sousa Coutinho. O documento autó- grafo de Ribeiro dos Santos intitulado Edições dos Clássicos de Bodoni tem uma nota que remete para o Marquês de Ponte de Lima, Mordomo-Mor e Inspector-Geral da Biblioteca: "Foi encomenda que fiz ao Marquês". Trata-se de uma lista muito minuciosa, indicando o formato, o tipo de caracteres (por exemplo, "cursivos") e mesmo o tipo de papel (por exemplo, "papel real fino") a que as edições a adquirir devem obedecer, notas reveladoras do conhecimento e interesse que Ribeiro dos Santos tinha sobre Bodoni. A aquisição, no entanto, só virá a verificar-se quando D. Rodrigo de Sousa Coutinho sucede ao Marquês de Ponte de Lima, já em 1802.

3 Se fosse necessário caracterizar os códices, diríamos que eles se distinguem: pelo esforço de sistematização do saber, numa abordagem temática sem limites; pela atenção dada à pesquisa e organização bibliográficas; pelo relevo atribuído às bibliotecas portuguesas em geral e à Real Biblioteca Pública da Corte em particular; pelo sentido de urgência no provimento bibliográfico da Real Biblioteca. É completamente redutor referir o Doutor António Ribeiro dos Santos como Bibliotecário da Real Biblioteca. No tempo dele, e depois dele, foram muitos os bibliotecários que passaram na instituição, e alguns deixaram a sua marca. Mas ele sobressaiu no exercício do cargo com muita sabedoria e conhecimento. E enquanto erguia a instituição, ia-lhe 
garantindo os recursos bibliográficos e financeiros que acabariam por distingui-la de outras bibliotecas portuguesas - uma instituição com mais de duzentos anos cuja estruturação tem um responsável. É hora de reconhecer este mérito a Ribeiro dos Santos.

\section{BIBLIOGRAFIA}

CABRAL, Maria Luísa. 2014. A Real Biblioteca e os Seus Criadores. Lisboa: Biblioteca Nacional de Portugal.

PEREIRA, José Esteves. 2005. O Pensamento Político em Portugal no Século XVIII: António Ribeiro dos Santos. 2. ed. Lisboa: Imprensa Nacional-Casa da Moeda.

POMBO, Olga. 1997. Leibniz e o Problema de uma Língua Universal. Lisboa: Junta Nacional de Investigação Científica e Técnica.

\section{NOTAS}

1. Trata-se dos Códices 4583-4732 (Obras ARS 1 - ARS 150) existentes na Biblioteca Nacional de Portugal, Reservados. Para facilitar a localização, usamos a cota da BNP (COD.) deixando de lado a cota original com a sigla do autor, ARS.

2. Sobre a mudança de Coimbra para Lisboa, temos a observação esclarecedora de António Ribeiro dos Santos: "Fragmento de um livro que escrevi sobre as Leis e Usos de Portugal e se seguia ao outro da Espanha Arábica que com ela se me perdeu na mudança da minha livraria de Coimbra para Lisboa" (BNP COD. 4671, 270).

3. D. Rodrigo de Sousa Coutinho acumula as funções de Ministro da Fazenda e de Inspector-Geral da Real Biblioteca entre Novembro de 1801 e Setembro de 1803.

\section{RESUMOS}

São cento e cinquenta os códices que António Ribeiro dos Santos legou à Real Biblioteca Pública da Corte. 0 cuidado posto na sua organização, a exaustividade com que o trabalho foi executado, a sucessão de originais, cópias e borrões fazem deste núcleo documental uma peça indispensável para compreender a intervenção pública e profissional de Ribeiro dos Santos, sobretudo no que se relaciona com a Real Biblioteca Pública, mas também o carácter e as opções filosóficas do autor. Os códices foram organizados tendo em vista preservar a memória de uma vida. Corporizam um manancial informativo que em duzentos anos despertou pouca atenção, constatação que proporcionou espaço para reflectir sobre a obra de Ribeiro dos Santos, escalpelizando o conteúdo e a organização dos códices. 
António Ribeiro dos Santos donated his one hundred fifty codices to the Real Biblioteca Pública da Corte (Royal Public Library). Their careful organization, the exhaustivity applied on their organization, the sequence of originals, copies and drafts, turns this set of documents into an indispensable source to understand the public and professional intervention of Ribeiro dos Santos, mainly in what concerns the Real Biblioteca, as much as they reveal the author's character, and his philosophical options. Codices were organized in order to preserve the memory of his professional life. They gather information which conveyed little attention during two hundred years, and this conclusion allowed the opportunity to reflect upon Ribeiro dos Santos works, digging into their content and thoroughly evaluating their organization.

Royal Public Library, António Ribeiro dos Santos, bibliographical collections, classification systems, Enlightenment

\section{ÍNDICE}

Palavras-chave: Real Biblioteca Pública da Corte, António Ribeiro dos Santos, colecções bibliográficas; sistemas de classificação, Iluminismo

\section{AUTOR}

\section{MARIA LUÍSA CABRAL}

CHAM, FCSH, Universidade NOVA de Lisboa, Portugal. e-mail: cabral1946@gmail.com Foi bibliotecária na Biblioteca Nacional de 1985 até 2011, data da sua aposentação, tendo desempenhado as funções de subdirectora (responsável pela criação da PORBASE) e directora de Serviços (responsável pela criação do Programa de Preservação e Conservação). Entre 1984 e 2011, leccionou sucessivamente nas Universidades de Lisboa, Évora e Porto e na Universidade Nova, Lisboa. É detentora de um MA in Library Management (Leeds Polytechnic, UK, 1983), de um mestrado em Património (Universidade Nova, Lisboa, 2009) e de um doutoramento em História Moderna (Universidade Nova, Lisboa, 2013). Tem publicados alguns livros e artigos sobre biblioteconomia e a história da Real Biblioteca Pública da Corte.

Librarian at the National Library, from 1985 to 2011. Deputy Director (responsible for the creation of PORBASE), and Head of Department (responsible for the Preservation and Conservation Programme). Between 1984 and 2011 successively lectured at Universidade Clássica de Lisboa, Universidade de Évora, Universidade do Porto and Universidade Nova, Lisboa. MA in Library Management (Leeds Polytechnic, UK, 1983), MA in Cultural Heritage (Universidade Nova, Lisboa, 2009), PhD Modern History (Universidade Nova, Lisboa, 2013). A few books, and several articles published both on librarianship issues, and the history of the Public Royal Library. 